\title{
BMJ Open Transitions of disability, disability-free life expectancy and health insurance among adults aged 50 and older in Mexico: a multistate life table analysis
}

To cite: Cabrero Castro JE, García-Peña C, Ramírez Aldana R. Transitions of disability, disability-free life expectancy and health insurance among adults aged 50 and older in Mexico: a multistate life table analysis. BMJ Open 2021;11:e045261. doi:10.1136/ bmjopen-2020-045261

- Prepublication history and additional supplemental material for this paper are available online. To view these files, please visit the journal online. (http://dx.doi.org/10.1136/ bmjopen-2020-045261).

Received 25 September 2020 Accepted 22 July 2021

Check for updates

(c) Author(s) (or their employer(s)) 2021. Re-use permitted under CC BY-NC. No commercial re-use. See rights and permissions. Published by BMJ.

${ }^{1}$ Programa de Maestría y Doctorado en Ciencias Médicas, Odontológicas y de la Salud, Universidad Nacional Autónoma de México, Coyoacan, Mexico

${ }^{2}$ Research Department, Instituto Nacional de Geriatría, Mexico City, Mexico

Correspondence to Dr Carmen García-Peña; mcgarcia@inger.gob.mx

\section{ABSTRACT}

Objectives To analyse the transitions of disability onset and recovery, estimate life expectancy (LE) with and without disability and explore the relation between insurance and disability patterns in the population aged $50+$ in Mexico.

Design Multistate life table analysis of data from a longitudinal cohort survey.

Setting Data came from the Mexican Health and Aging Study, a longitudinal and representative survey of older adults in Mexico.

Participants 10651 individuals aged $50+$ interviewed in 2012 and 2015, including those who died between waves. Primary and secondary outcome measures Disability is measured using the activities of daily living (ADL) scale. Transition rates between disability free, $A D L$ disabled and death were employed to estimate total life expectancy (TLE) and disability-free life expectancy (DFLE).

Results $46 \%$ of the individuals who reported an ADL limitation in 2012 recover from disability by 2015. TLE at age 60 for people without ADL limitations is 30 years $(95 \%$ $\mathrm{Cl} 28.9$ to 31), out of which 4.7 years ( $95 \% \mathrm{Cl} 4.1$ to 5.4 ) are lived with ADL limitations, while TLE at age 60 in the initially disabled is 18.7 years ( $(95 \% \mathrm{Cl} 17.3$ to 20$)$, with 9.4 years $(95 \% \mathrm{Cl} 8.4$ to 10.3$)$ lived with disability. DFLE at age 60 in people with social security is 24.2 years $(95 \% \mathrm{Cl}$ 23.3 to 25.2), in people with public insurance is 24.6 years $(95 \% \mathrm{Cl} 23.7$ to 25.4 ) and in uninsured people is 26.9 years $(95 \% \mathrm{Cl} 25.9$ to 27.9$)$.

Conclusions In Mexico, a substantial proportion of ADL disabled individuals recover from disability. Nevertheless, initially disabled individuals have a considerably lower DFLE regardless of age when compared with initially active individuals. There appeared to be no differences in terms of disability and LEs between the individuals with social security and public insurance.

\section{INTRODUCTION}

Biologically, ageing is associated with damage at the cellular and molecular levels, which, over time, reduces physiological reserves, increasing the risk of disease and death. Vision, mobility and hearing impairments may occur as a result of biological events, leading to functional deterioration and, consequently,
Strengths and limitations of this study

- This research analysed the transitions of the pro cess of disability using a multistate life table with longitudinal data from a national survey estimating disability-free life expectancy and life expectancy with limitations in activities of daily living, including relevant sociodemographic characteristics.

- This study introduced healthcare insurance groups to the analyses to acknowledge the complexity of the Mexican healthcare system and study the relation between insurance and disability patterns.

- This study has some limitations regarding the sample sizes when dividing by insurance and disability transitions, particularly in those uninsured and initially disabled with small subsamples that could have led to the overestimation of disability-free and total life expectancy.

- This methodology does not allow to analyse causal effects and results should be interpreted as associations.

disability. ${ }^{2}$ Specifically, the ageing process is associated to and can produce functional impairment and disability. ${ }^{3}$

Previous research has studied disability as a process, not as a static end stage. Transitions from health to disability and finally to death among older adults represent a complex path that allows for recovery from disability and the transition back to a less disabled or fully functional state. Also, as this process is made up of different transitions, skipping a state within the process is also possible. ${ }^{4-7}$ These characteristics can translate into different patterns of transitions among different population groups. In 2012, the prevalence of disability measured through the limitation in activities of daily living (ADL) among adults aged $60+$ in Mexico was $22 \%$ and $31 \%$, according to the National Health and Nutrition Survey and the Mexican Health and Aging Study (MHAS), respectively. ${ }^{89}$ As for recovery from 
disability, studies have found up to $20 \%$ of partial or full recovery in Mexican older adults with ADL limitations in the span of 11 years. ${ }^{67}$ Regarding life expectancy and disability in adults aged 60+ years in Mexico, life expectancy is 22 years. However, on average, 3.9 of these years are lived with functional limitations. ${ }^{10}$ Moreover, active life expectancy has decreased by 1.13 years in Mexican population when comparing 1932-1941 and 1943-1952 birth cohorts in adults aged $60-69 .{ }^{11}$ This evidence suggests a rising prevalence and longer duration of disability among successive cohorts.

The transitions between the different functional states in the disablement process depend on the external environment and individual attributes, as well as on the exposure to risk factors and health protection factors during the life course. ${ }^{2}{ }^{12}$ Some of the factors that have been found to be related with changes in disability are sex, education, marital status, ${ }^{6}$ income, health variables such as prevalence of non-communicable diseases, self-rated health ${ }^{13}$ and other factors like insurance coverage. ${ }^{14}$

Regarding health insurance, Mexico has several public institutions with different coverage schemes, funding sources and service providers, and they target different population groups. The Mexican Institute for Social Security (Instituto Mexicano del Seguro Social, IMSS) and the Institute for Social Security and Services for State Workers (Instituto de Seguridad y Servicios Sociales para los Trabajadores del Estado, ISSSTE) are the main social security institutions with full coverage and insurance for workers with formal employment in the private industry or the state. Popular Insurance (Seguro Popular) was created in 2003 and until 2019 it was a publicly funded health insurance scheme aimed at covering the large uninsured population. ${ }^{15}$ Nevertheless, Seguro Popular only offers coverage for a limited package of, mainly, primary and secondary interventions. Besides, availability of medical units, health services, technology and health professionals are also different among insurance schemes. Choosing between insurance schemes is not possible as they are targeted at the aforementioned specific populations. These three institutions cover more than threequarters of the population. By 2000, enrolment in public healthcare institutions in the older adult population was $52.9 \%$ and saw an expansion to $83.3 \%$ in $2012 .{ }^{16}$ A small proportion of households use private insurance or out-ofpocket expenditures to cover health events. ${ }^{17}$

Insurance has been associated with a higher likelihood of accessing medical care, follow-up care, prescription medicines and a better health status. ${ }^{18}$ Previous findings in Mexico suggest that beyond socioeconomic attributes and health conditions of the individuals, the availability of health insurance plays an important role in increasing access to healthcare services, the utilisation of diagnostic tests and self-reporting diagnosis (disease awareness), but has limited effects on the probability of receiving treatment. ${ }^{19-21}$ Despite the evidence, availability of health insurance may not necessarily guarantee effective treatment or a positive health impact.
There are few previous studies that analyse the process of disability, its multiple transitions, the reversibility of the process and the contribution of this process to the expansion of disability in older adults in Mexico. In addition, none of the previous research acknowledges the relation of insurance schemes variability in terms of coverage for specific health interventions, availability of geriatric services, rehabilitation units and health professionals, and ADL disability.

This research is focused on the study of patterns of disability onset and recovery, and the estimation of life expectancy with and without disability in the population aged 50+ years in Mexico. Also, we compare these measures between uninsured population and people enrolled in social security and public insurance to gain insight into a possible association between insurance and disability patterns.

\section{METHODS}

\section{Data}

Data came from the MHAS, which is a national longitudinal study of adults aged 50+ years in Mexico. The survey provides information about sociodemographic and health characteristics, enabling the exploration of the ageing process, and the impact of diseases and disability on the population. The baseline survey was conducted in 2001 with follow-up interviews in 2003, 2012, 2015 and $2018 .^{22}$

For our analyses, we included individuals aged 50 and older interviewed in both 2012 and 2015, including those who died between waves $(\mathrm{n}=13944)$. However, 1669 participants were eliminated from the complete sample due to the lack of a complete questionnaire for the variables of interest. The excluded participants had sociodemographic and health characteristics similar to the rest of the sample (online supplemental table 1).

The analyses were carried out initially on a sample of 12275 individuals and then on groups according to their health insurance scheme. Those groups were social security (IMSS and ISSSTE), public insurance (Seguro Popular) and uninsured population. Private insurance was not included because it represented less than $1 \%$ of the total sample. The final sample grouped by health insurance had 10651 individuals (86.77\% of 12275 ).

The concept of disability became operational through the self-reporting of ADL using a modified version of the Katz Index,${ }^{23}$ which explores if the respondent required help to perform any of the following five activities: walking, bathing, eating, getting in/out of bed and using the toilet. These activities reflect the functional capacities that are essential to survive and be independent, and that tend to deteriorate at an older age. The need for help or the difficulty in carrying out one or more of the five activities mentioned was considered an ADL disability. Those individuals who reported not needing help, nor having difficulty in all the five activities, were called active. 


\section{Analytical strategy}

A multistate life table (MSLT) was adopted to longitudinally analyse the transition between states according to ADL disability, converting the longitudinal information into estimates of disability-free life expectancy and life expectancy with limitations in daily life activities. An MSLT is a generalisation of a life table, in which instead of just having two states (living and death), a set of three or more states can be modelled through a continuous-time Markov chain. In this case, the transition occurs between three states: active, ADL disabled and dead as an absorbing state (online supplemental figure 1). The MSLT describes the distribution of the cohort in each state according to ADL disability by age. It also shows the time the cohort is expected to remain in each state, considering age as a duration variable in intervals of 1 year.

Two methods were used to estimate the transition rates, the Nelson-Aalen estimators (non-parametric) and the exposure-occurrence rates (parametric). Only results based on exposure-occurrence method are presented in this paper since the results obtained by the Nelson-Aalen estimator were similar. Later on, it is possible to construct a multistate survival function that contains the transition and occupation probabilities associated with each state. The expected occupation times derive from the occupation probabilities, the sum of the occupation times from a defined age determines the life expectancy of the cohort for that age.

Based on the above information, the disability-free life expectancy, the disabled life expectancy (DLE) and the total life expectancy were estimated at ages 60,70 and 80 . For a more precise analysis, in addition to estimating life expectancy regardless of initial functional status (known as population-based life expectancy), life expectancy is also estimated based on the condition of being physically healthy or ADL disabled at ages 60, 70 and 80 (known as status-based life expectancy or SBLE). The analysis was performed on the complete sample and on groups according to their health insurance scheme in order to compare life expectancies.

Hazard models including covariates and considering state transitions as strata were fitted as part of the MSLT analysis for a set of three variables chosen from previous analyses performed through linear models in which we observed a significant relationship between them and all the transitions of disability. These were binary covariates concerning sex, insurance scheme and diabetes, resulting in 12 different combinations of possible values and multistate survival curves (online supplemental figure 2).

The method corresponds to the analysis of life stories that is mainly implemented in the Biography library available in . $^{24}$

\section{Patient and public involvement}

Patients and the public were not directly involved in this study since we used publicly available data from a national survey. Despite this, results will be shared with decision-makers directly involved in healthy ageing policies in Mexico.

\section{RESULTS}

Table 1 shows the sociodemographic and health characteristics of the 2012 sample. The average age was 64.9 years with a higher representation of women. Half of the individuals report having $6+$ years of education, $69 \%$ report being married or cohabiting, $58 \%$ of respondents live in populations of 100000 inhabitants or more, $74.96 \%$ have social security or public insurance while $11.8 \%$ are uninsured.

In terms of health, hypertension was the most frequent disease with a prevalence of $44.7 \%$, followed by diabetes with $23.5 \%$. The presence of acute health events, such as a heart attack, was also reported in $3.6 \%$ of the respondents. Further, $35.4 \%$ of the respondents report having good health, $51.5 \%$ fair and $13.1 \%$ bad.

During 2012, of 1614 older adults who reported an ADL limitation, $58.2 \%$ reported one, $22.1 \%$ two and $19.7 \%$ three or more. For 2015, the number of limitations presented by the individuals increased; of 1897 respondents, $51.8 \%$ reported one, $20.3 \%$ two and $27.9 \%$ three or more.

In both years, transferring in and out of bed was the activity most frequently reported with a performance limitation in more than half of the respondents classified as ADL disabled (54\%, 2012; 58\%, 2015), followed by walking, using the toilet, bathing and, finally, eating (online supplemental table 2).

Regarding the transitions between the states active, ADL disabled and dead in 2012-2015, there was an increase in the prevalence of disability from $13.1 \%$ to $15.4 \%$, despite $46 \%$ of the individuals who reported a limitation performing ADL in 2012 recover from disability by 2015 . Of the total sample, $6 \%$ died by 2015 , and of the ADL disabled, $14.2 \%$ died. Moreover, $77.8 \%$ of all respondents remained in the same state in both years (figure 1).

As age increases, the probability of being active drops while dying rises. For a 50 years old, the probability of being ADL disabled reaches its peak at 86 years (21\%). Also, from this age on, the cohort is more likely to have a disability or die $(50.5 \%)$ when compared with being in an active state $(49.5 \%)$. All these probabilities are conditional on reaching 50 years old (online supplemental table 3 and figure 2).

Analysing the cumulative transition rates for all the transitions at ages 70,80 and 90, the disability incidence rates were $0.2,0.5$ and 1.4 , while the recovery rates from disability were 3.2, 4.3 and 5.1. Regarding the risk of death, it was higher among disabled individuals, with cumulative rates of $0.3,0.6$ and 1.4 , contrasting with 0.02 , 0.1 and 0.3 for non-disabled individuals (online supplemental table 4).

Overall, women aged 50 have higher probabilities of transiting to disability than men at all ages after 50 , and this also happens with the probabilities of transiting to 
Table 1 Sociodemographic and health characteristics at baseline (2012)

\begin{tabular}{llll}
\hline & Total & Male & Female \\
\hline $\mathrm{n}$ & 12275 & 5212 & 7063 \\
ADL disability & & & \\
$\quad$ Active & 86.85 & 90.18 & 84.4 \\
$\quad$ Disabled & 13.15 & 9.82 & 15.6 \\
Socioeconomic characteristics & & & \\
\hline
\end{tabular}

\section{Age}

$\begin{array}{llll}\text { Average* }^{*} & 64.94 & 65.7 & 64.39 \\ \leq 60 & 35.63 & 30.22 & 39.61 \\ 61-70 & 37.95 & 41.65 & 35.21 \\ 71-80 & 19.76 & 20.7 & 19.06 \\ \geq 81 & 6.67 & 7.43 & 6.12\end{array}$

Sex

$\begin{array}{ll}\text { Female } & 57.54 \\ \text { Male } & 42.46\end{array}$

Education

$1-5$ years of education $\quad 49.08 \quad 45.99 \quad 51.37$

$6+$ years of education $\quad 50.92 \quad 54.01 \quad 48.64$

Marital status

Married/cohabiting $\quad 69.03 \quad 82.62 \quad 59$

Level of urbanisation

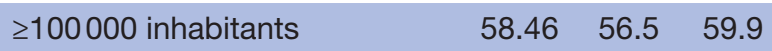

Healthcare enrolment

\begin{tabular}{|c|c|c|c|}
\hline Social security (IMSS, ISSSTE) & 49.53 & 48.71 & 50.13 \\
\hline $\begin{array}{l}\text { Public insurance (Seguro } \\
\text { Popular) }\end{array}$ & 25.43 & 24.62 & 26.02 \\
\hline Private insurance & 0.96 & 1.19 & 0.8 \\
\hline Uninsured & 11.80 & 13.66 & 10.45 \\
\hline \multicolumn{4}{|l|}{ Health characteristics } \\
\hline Hypertension & 44.73 & 36.63 & 50.7 \\
\hline Diabetes & 23.55 & 20.34 & 25.92 \\
\hline Arthritis & 14.07 & 9.34 & 17.56 \\
\hline Cancer & 2.18 & 1.71 & 2.53 \\
\hline Heart attack & 3.65 & 4.49 & 3.03 \\
\hline Lung disease & 6.03 & 4.66 & 7.04 \\
\hline \multicolumn{4}{|l|}{ Self-reported health measure } \\
\hline Good & 35.38 & 41.06 & 31.19 \\
\hline Fair & 51.51 & 47.85 & 54.21 \\
\hline Bad & 13.11 & 11.09 & 14.6 \\
\hline
\end{tabular}

*SD total=9.38, male=9.34, female=9.38.

ADL, activities of daily living; IMSS, Instituto Mexicano del Seguro Social; ISSSTE, Instituto de Seguridad y Servicios Sociales para los Trabajadores del Estado.

death until 69 years old. From this age on, men have higher probabilities of dying conditional on reaching 50 years old (figure 2).

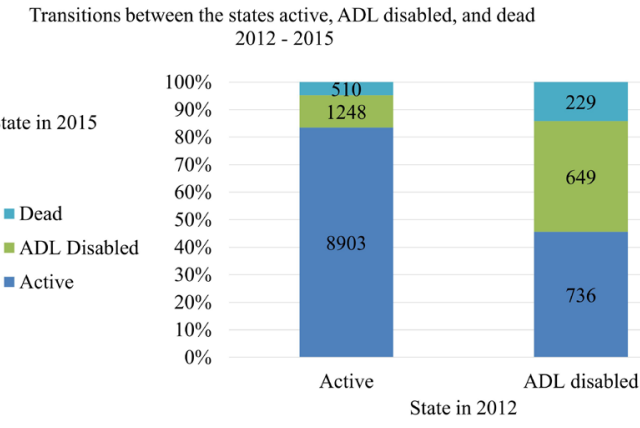

Figure 1 Transitions across states and time. A total of 10 661 were active and 1614 were ADL disabled at baseline. Colours represent the percentage at final state in 2015. ADL, activities of daily living.

Cumulative disability incidence rate was higher among women (eg, 0.6 vs 0.39 at age $80 ; 1.63$ vs 1.07 at age 90 ), as well as the recovery rate from disability compared with men (eg, 4.35 vs 3.79 at age $80 ; 5.09$ vs 4.52 at age 90 ). However, $95 \%$ CIs overlap between groups in the latter. On the other hand, it appears that there are no differences in the risk of death between sexes (online supplemental figure 3). Considering the models including covariates, diabetes appeared to be related mainly to a higher mortality transition (online supplemental figure 2).

Concerning life expectancies (figure 3 and online supplemental table 5), and considering that these results are conditional on reaching 50 years old, the total life expectancy at age 60 is 30 years, out of which almost 5 years are lived with ADL limitations. The total life expectancy at age 70 is 20 years, with a disability-free life expectancy of just over 15 years. The total life expectancy at age 80 is almost 11 years, out of which 7 years are lived without limitations.

For the three age groups, 60, 70 and 80, despite the fact that the total life expectancy in the initially ADL disabled is only 2 years less compared with those initially active, the ADL disabled expect to live almost twice as long with limitations. As an example, those initially healthy at age 80 expect to live a proportionally longer time free of disability compared with those initially disabled who are 20 years younger.

Regarding total life expectancy and sex there appear to be no differences between women and men; nevertheless, there is a significant difference in the proportion of time lived with disability with women spending on average 1.2 more years with disability compared with men and 1.4 fewer years free of disability across the three age thresholds. This difference remains regardless of the initial functional status.

When comparing the uninsured population against the group of people enrolled in social security services and public insurance, the latter have a lower total life expectancy mainly because of a lower disability-free life expectancy, but also have a higher DLE. Meanwhile, life expectancies between the social security and public 

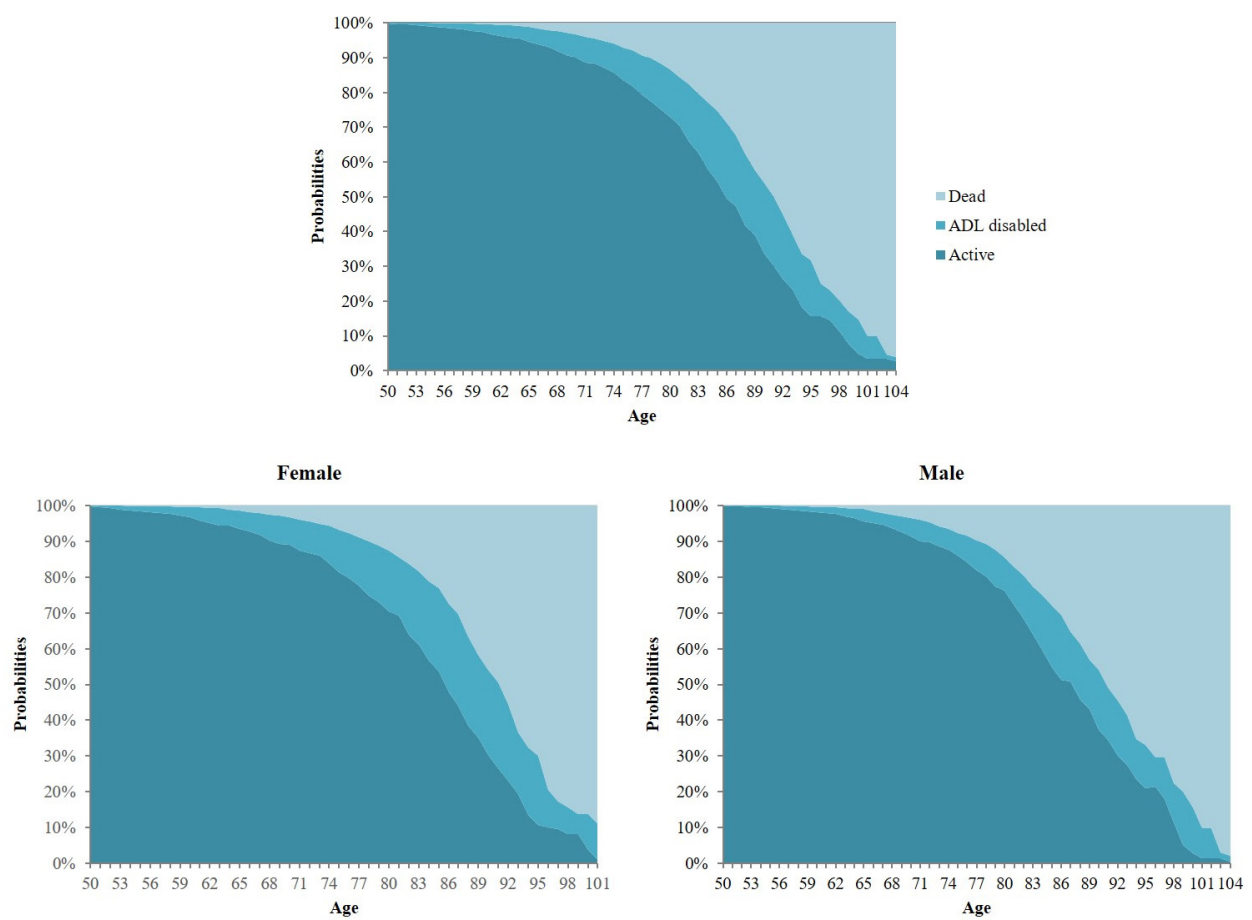

Figure 2 The multistate survival function shows the state occupation probabilities predicted from empirical transition rates. Full sample and stratified by sex curves are shown. ADL, activities of daily living.

insurance groups are similar with overlapping CIs (table 2). This is reinforced when analysing the cumulative transition rates where public insurance and social security have higher disability incidence rates than uninsured population (eg, 0.56 vs 0.52 vs 0.45 at age $80 ; 1.41$ vs 1.46 vs 1.13 at age 90$)$. However, $95 \%$ CIs overlap between the three insurance groups in all transitions (online supplemental figure 4).

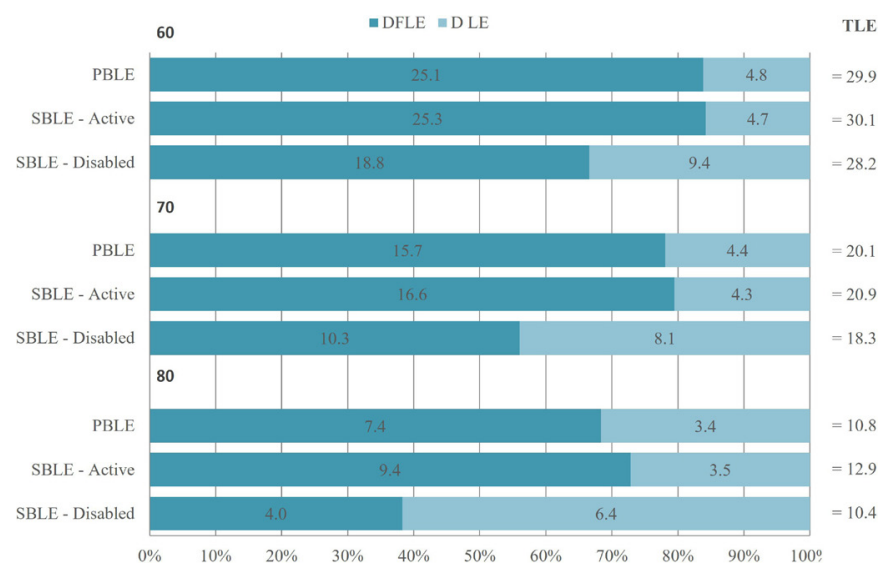

Figure 3 PBLE and SBLE in initially active and disabled states at ages 60,70 and 80 . The proportion of DFLE and DLE is shown for each TLE bar. DFLE, disability-free life expectancy; DLE, disabled life expectancy; PBLE, populationbased life expectancy; SBLE, status-based life expectancy; TLE, total life expectancy.

\section{DISCUSSION}

The purpose of this paper was to have a better understanding of the patterns of disability, including its transitions, state occupations and other components that allow the estimation of disability onset, recovery and mortality, as well as life expectancy with and without disability in the population aged $50+$ in Mexico. In addition, these measures were used to acknowledge possible differences, if any, in disability among groups with different health insurance schemes.

An MSLT model was adopted to analyse the dynamics of functional health by age and to calculate probabilities of transition and occupation of disability-free, ADL disabled and dead states. Also, this method was used to estimate the years lived with disability in our sample, which can account for a significant proportion of life expectancy.

The results support previous findings in literature which show that functionality does not follow a linear process of deterioration from ageing. Transitions between functional states occur in both directions, with improvement and deterioration of functional capacity over time, the latter taking place with more frequency as population ages, extending life along with disability. ${ }^{4-7}$

Nearly half of the individuals with a functional limitation at baseline recovered from ADL disability by 2015. This is described in other studies where individuals partially or fully recovered functionality over time, suggesting that disablement processes are reversible in certain conditions. ${ }^{67}$ In our study, some conditions that seem to affect recovery are lower age, being female and being nondiabetic since the transition probabilities were higher compared with reference categories (in yellow, online 
Table 2 Life expectancies at ages 60, 70 and 80, grouped by health insurance scheme and sex including 95\% Cls

DFLE DLE TLE

\begin{tabular}{|c|c|c|c|c|c|c|}
\hline \multicolumn{7}{|c|}{ Social security (IMSS, ISSSTE), $\mathrm{n}=6080$} \\
\hline 60 & \multicolumn{2}{|l|}{24.2 (23.3 to 25.2 ) } & \multicolumn{2}{|l|}{4.8 (4 to 5.7$)$} & \multicolumn{2}{|l|}{29.1 (27.7 to 30.4$)$} \\
\hline 70 & \multicolumn{2}{|l|}{14.8 (13.9 to 15.7$)$} & \multicolumn{2}{|l|}{4.4 (3.5 to 5.3$)$} & \multicolumn{2}{|l|}{19.2 (17.9 to 20.5$)$} \\
\hline 80 & \multicolumn{2}{|l|}{$6.6(5.7$ to 7.5$)$} & \multicolumn{2}{|l|}{3.4 (2.6 to 4.2$)$} & \multicolumn{2}{|l|}{$10(8.7$ to 11.3$)$} \\
\hline \multicolumn{7}{|c|}{ Public insurance (Seguro Popular), $n=3121$} \\
\hline 60 & \multicolumn{2}{|c|}{$24.6(23.7$ to 25.4$)$} & \multicolumn{2}{|l|}{5.1 (4.4 to 5.8$)$} & \multicolumn{2}{|l|}{29.7 (28.5 to 30.9$)$} \\
\hline 70 & \multicolumn{2}{|l|}{$15.2(14.4$ to 16$)$} & \multicolumn{2}{|l|}{4.6 (3.9 to 5.3 ) } & \multicolumn{2}{|l|}{19.8 (18.7 to 21$)$} \\
\hline 80 & \multicolumn{2}{|l|}{$7.0(6.2$ to 7.7$)$} & \multicolumn{2}{|l|}{$3.6(2.9$ to 4.3$)$} & \multicolumn{2}{|l|}{10.6 (9.5 to 11.8$)$} \\
\hline \multicolumn{7}{|c|}{ Uninsured, $n=1450$} \\
\hline 60 & \multicolumn{2}{|l|}{26.9 (25.9 to 27.9$)$} & \multicolumn{2}{|l|}{4.6 (3.9 to 5.2$)$} & \multicolumn{2}{|l|}{31.5 (30.3 to 32.6 ) } \\
\hline 70 & \multicolumn{2}{|l|}{17.5 (16.5 to 18.4$)$} & \multicolumn{2}{|l|}{4.2 (3.5 to 4.8$)$} & \multicolumn{2}{|l|}{21.6 (20.5 to 22.8$)$} \\
\hline 80 & \multicolumn{2}{|l|}{$8.9(7.9$ to 9.8$)$} & \multicolumn{2}{|l|}{3.3 (2.7 to 3.9$)$} & \multicolumn{2}{|l|}{$12.2(11.1$ to 13.3$)$} \\
\hline & \multicolumn{2}{|l|}{ DFLE } & \multicolumn{2}{|l|}{ DLE } & \multicolumn{2}{|l|}{ TLE } \\
\hline Social security & $\mathbf{F}$ & $\mathbf{M}$ & $\mathbf{F}$ & $\mathbf{M}$ & $\mathbf{F}$ & $\mathbf{M}$ \\
\hline 60 & 23.5 (22.2 to 24.9$)$ & 25.2 (23.6 to 26.8$)$ & 5.7 (4.5 to 6.8$)$ & 3.9 (2.5 to 5.4$)$ & 29.2 (27.5 to 30.9 ) & $\begin{array}{l}29.1(26.5 \text { to } \\
31.8)\end{array}$ \\
\hline 70 & 14.2 (12.9 to 15.6$)$ & 15.6 (14.1 to 17.2$)$ & 5.1 (4 to 6.3$)$ & 3.6 (2.2 to 5.1$)$ & 19.3 (17.6 to 21$)$ & 19.3 (16.6 to 22$)$ \\
\hline 80 & 6.1 (4.8 to 7.4 ) & 7.3 (5.8 to 8.7 ) & $3.9(2.7$ to 5$)$ & 2.9 (1.4 to 4.4$)$ & $10(8.3$ to 11.7$)$ & 10.2 (7.6 to 12.8$)$ \\
\hline Public insurance & $\mathbf{F}$ & M & $\mathbf{F}$ & $\mathbf{M}$ & $\mathbf{F}$ & M \\
\hline 60 & 23.3 (22.2 to 24.3 ) & 25.8 (25 to 26.6 ) & 5.5 (4.1 to 6.8 ) & 4.5 (3.6 to 5.4$)$ & 28.7 (26.7 to 30.7 ) & $\begin{array}{l}30.3(29.1 \text { to } \\
31.6)\end{array}$ \\
\hline 70 & 14 (13 to 15.1$)$ & $16.3(15.5$ to 17.1$)$ & 4.9 (3.6 to 6.2$)$ & 4.1 (3.2 to 5.1$)$ & 18.9 (16.9 to 20.9$)$ & $\begin{array}{l}20.4 \text { (19.2 to } \\
21.7)\end{array}$ \\
\hline 80 & 6.1 (5.1 to 7 ) & 7.8 (7 to 8.6 ) & 3.8 (2.5 to 5.1$)$ & 3.3 (2.3 to 4.2 ) & 9.9 (7.9 to 11.8$)$ & 11 (9.8 to 12.2 ) \\
\hline Uninsured & & & & & & \\
\hline 60 & 26.5 (26 to 27 ) & 27.2 (27 to 27.5$)$ & 6.3 (5.9 to 6.6 ) & 3.1 (3 to 3.2 ) & 32.7 (32.2 to 33.3 ) & $\begin{array}{l}30.4 \text { (30.2 to } \\
30.5)\end{array}$ \\
\hline 70 & 17.2 (16.7 to 17.7$)$ & 17.7 (17.5 to 17.9$)$ & 5.7 (5.3 to 6) & 2.9 (2.7 to 3 ) & 22.9 (22.3 to 23.4) & $\begin{array}{l}20.5 \text { (20.4 to } \\
20.7)\end{array}$ \\
\hline 80 & 8.7 (8.2 to 9.1$)$ & 9.1 (8.8 to 9.3 ) & 4.6 (4.3 to 5 ) & 2.2 (2.1 to 2.4 ) & 13.3 (12.8 to 13.8$)$ & $\begin{array}{l}11.3(11.1 \text { to } \\
11.5)\end{array}$ \\
\hline
\end{tabular}

DFLE, disability-free life expectancy; DLE, disabled life expectancy; F, female; IMSS, Instituto Mexicano del Seguro Social; ISSSTE, Instituto de Seguridad y Servicios Sociales para los Trabajadores del Estado; M, male; TLE, total life expectancy.

supplemental figure 2). This is particularly relevant in the design of rehabilitation programmes for older adults. Also, the number of limitations presented by the individuals increased by 2015 compared with baseline, showing that severity of disability increases with age. Bathing was the activity with a performance limitation that showed proportionally the greatest rise in limitation frequency, while using the toilet was the one with the lowest.

Regarding probabilities, ADL disability reaches its peak at 86 years; from age 86 onwards, the probability of dying is greater than recovering functional health in individuals with disability, conditional on reaching 50 years old. This is consistent with previous findings that individuals aged 85 and older are more likely to die within the next year than to recover to a disability-free life. ${ }^{25}$
Next, the total life expectancy in the initially ADL disabled is 2 years lower and they live two times more with limitations than those initially active in the three age groups (60, 70 and 80). This means that although disability could be a reversible process, a proportion of individuals do not recover once disability onset occurs. In this regard, the concept of compression of morbidity states that the increase in life expectancy in a population would be accompanied by the compression of disability to a shorter span of time near the end of life. ${ }^{26}$ In contrast, the opposite concept about the expansion of morbidity or disability affirms that in some contexts, poor early-life conditions have a delayed effect on the onset of noncommunicable chronic diseases, hence a longer proportion of life lived with disability despite the adoption of 
medical technologies that improve survivorship but fail to reduce disability. ${ }^{27}$ This is reinforced by the concept of dynamic equilibrium in which prevalence is increased by reducing the severity of the disease or eliminating lethal sequelae thus increasing the life span in a morbid state, in this case, disability. ${ }^{28}$

Previous studies found increasing trends in life expectancy and expansion of disability accompanied by a rise in obesity, cardiovascular and metabolic conditions in Mexico. ${ }^{11}$ This study adds information about the expansion of disability with evidence of a considerably higher DLE in previously disabled people regardless of the age group, and in some groups, more than half of the total life expectancy is lived with an ADL limitation. Moreover, cumulative rates for incidence of disability were higher in women than in men, in contrast with the recovery of disability or mortality rates which did not appear to be statistically different (online supplemental figure 3 ). This means that sex-specific differences in patterns of disability are driven by incidence and not by the other transitions. Therefore, men expect to live more time without disability at all age thresholds and this is consistent when divided by insurance.

This study has some limitations regarding the sample sizes when dividing by insurance and each insurance group by disability transitions, particularly in those uninsured and initially disabled with small subsamples that could have led to the overestimation of disability-free and total life expectancy (online supplemental table 6 ). These led to paradoxical results with a significantly higher disability-free life expectancy in uninsured individuals when compared with the other groups.

Despite this, there were some factors that at least theoretically may have contributed to the lower DFLE in the uninsured group. First, the lower observed prevalence of several chronic conditions at baseline, as an example, the uninsured group has a $10 \%$ less prevalence of hypertension among women and 6\%-15\% less among men compared with insured individuals. The uninsured group also shows a lower prevalence of diabetes, arthritis and other chronic and acute conditions that are related to the incidence of disability and lower life expectancy. ${ }^{29}$ Besides, the prevalence of ADL disability at baseline is also lower in uninsured individuals regardless of sex (online supplemental table 7). As expressed in the previous analyses of SBLE, disabled individuals at baseline have lower disability-free and total life expectancy, hence, a lower prevalence of ADL disability at baseline in uninsured individuals will likely impact raw life expectancy.

The higher prevalence of several conditions in insured individuals may be because individuals with underlying conditions including disability are more likely to seek health insurance and adverse selection has been previously identified in social security insurance in Mexico. ${ }^{30} 31$ Another factor that may contribute to this is the previously stated effect of health insurance in the increase of utilisation of diagnostic tests and disease awareness but limited effects on the probability of receiving treatment, ${ }^{19-21}$ thus underdiagnosis of non-lethal conditions is likely higher in the uninsured group. However, more empirical data and a bigger sample are needed to set up a statistically valid model in terms of sample sizes of specific groups.

Other limitations were inherent of MSLT methodology where individuals are assumed to experience only one transition between the two waves of the survey, missing short transitions occurring between 2012 and 2015. This may result in an underestimation of the frequency of transitions between functional states, especially at younger ages. In addition, data about the specific time when transitions occur are not available; assuming transitions occur in the middle of the period does not allow to adjust transition probabilities to the real duration of state occupation.

Despite the limitations, this research contributes to bringing awareness about disability expansion and its underlying transition patterns, and not only total life expectancy, as a measure of successful ageing. These findings may integrate evidence to acknowledge the need and relevance of investing resources to improve ageing conditions and reduce time lived with disability.

\section{CONCLUSION}

This research suggests that the process of disability is nonlinear and each of its transitions should be analysed, along with the initial state occupation as it sets the following transition. In Mexico, a substantial proportion of ADL disabled individuals recover from disability. Nevertheless, initially disabled individuals have a considerably lower disability-free life expectancy regardless of age when compared with those initially active. Also, women live more years with disability compared with men at all age thresholds and this is mainly driven by the disability incidence transition. There appeared to be no differences in terms of disability and life expectancies between the individuals with social security and public insurance.

A recommendation is made to encourage the inclusion of specific transition analysis in future research, which could help model disability dynamics within the population, and health insurance schemes to acknowledge variability and contrast disability. The methods used in these analyses could be employed in the development of new indicators to estimate the expansion of disability and to measure the effectiveness of programmes related to prevention and rehabilitation from disability.

Acknowledgements The authors thank the support from the Instituto Nacional de Geriatría, Universidad Nacional Autónoma de México and Consejo Nacional de Ciencia y Tecnología.

Contributors JECC conceptualised the study, carried out the analyses, interpreted the data and wrote the manuscript. MCG-P helped in planning the methodology, interpreting the data, and supervised, edited and reviewed the manuscript. RRA helped in planning the methodology, carrying out the analyses, interpreting the data, and supervised, edited and reviewed the manuscript.

Funding The MHAS is partly sponsored by the National Institutes of Health/National Institute on Aging (grant number R01AG018016) in the USA and the National Institute of Statistics and Geography (INEGI) in Mexico. In addition, this project was supported by the Consejo Nacional de Ciencia y Tecnología (CVU 547263) in Mexico, and a grant from the Secretaría de Educación, Ciencia, Tecnología e Innovación 
de la Ciudad de México CM-SECTEI/200/2020 "Red Colaborativa de Investigación Traslacional para el Envejecimiento Saludable de la Ciudad de México (RECITES)". Competing interests None declared.

Patient consent for publication Not required.

Ethics approval This work was approved by the Ethics Committee from the Instituto Nacional de Geriatría in Mexico (DI-Pl-001/2020).

Provenance and peer review Not commissioned; externally peer reviewed.

Data availability statement Data are available in a public, open access repository. All data relevant to the study are included in the article or uploaded as supplementary information. The raw data poses no risk to the anonymity of individuals as it draws on publicly available reports and can be found in http://www. mhasweb.org/Data.aspx.

Supplemental material This content has been supplied by the author(s). It has not been vetted by BMJ Publishing Group Limited (BMJ) and may not have been peer-reviewed. Any opinions or recommendations discussed are solely those of the author(s) and are not endorsed by BMJ. BMJ disclaims all liability and responsibility arising from any reliance placed on the content. Where the content includes any translated material, BMJ does not warrant the accuracy and reliability of the translations (including but not limited to local regulations, clinical guidelines, terminology, drug names and drug dosages), and is not responsible for any error and/or omissions arising from translation and adaptation or otherwise

Open access This is an open access article distributed in accordance with the Creative Commons Attribution Non Commercial (CC BY-NC 4.0) license, which permits others to distribute, remix, adapt, build upon this work non-commercially, and license their derivative works on different terms, provided the original work is properly cited, appropriate credit is given, any changes made indicated, and the use is non-commercial. See: http://creativecommons.org/licenses/by-nc/4.0/.

\section{ORCID iDs}

Jose Eduardo Cabrero Castro http://orcid.org/0000-0003-4976-1989

Carmen García-Peña http://orcid.org/0000-0002-9380-6964

\section{REFERENCES}

1 Steves CJ, Spector TD, Jackson SHD, Ageing JSH. Ageing, genes, environment and epigenetics: what twin studies tell us now, and in the future. Age Ageing 2012;41:581-6.

2 World Health Organization. Chapter 2, envejecimiento saludable. In: Informe Mundial sobre El Envejecimiento Y La Salud. Geneva: World Health Organization, 2015: 27-42.

3 Gutiérrez Robledo LM, García Peña MC, Jiménez Bolón JE. Envejecimiento Y dependencia. Realidades Y previsión para Los próximos años. México: Academia Nacional de Medicina, 2014: 191.

4 Verbrugge LM, Jette AM. The disablement process. Soc Sci Med 1994;38:1-14.

5 Peek MK, Ottenbacher KJ, Markides KS, et al. Examining the disablement process among older Mexican American adults. Soc Sci Med 2003;57:413-25.

6 Díaz-Venegas C, De La Vega S, Wong R. Transitions in activities of daily living in Mexico, 2001-2012. Salud Publica Mex 2015;57:54-61.

7 Díaz-Venegas C, Wong R. Trajectories of limitations in activities of daily living among older adults in Mexico, 2001-2012. Disabil Health J 2016;9:524-32

8 Mexican Health and Aging Study Web. Mexican health and aging study. Mexico (Mx): Mexican Health and Aging Study Web, c2012. http://www.mhasweb.org/Data.aspx

9 Gutiérrez Robledo LM, Téllez Rojo MM, Manrique Espinoza B, et al. Encuesta Nacional de Salud Y Nutrición 2012: Evidencia para La política pública en salud. Discapacidad Y dependencia en adultos mayores mexicanos. México (Mx): Instituto Nacional de Salud Pública-Secretaría de Salud, 2012. https://ensanut.insp.mx/ encuestas/ensanut2012/doctos/analiticos/DiscapacidAdultMayor.pdf

10 Global Burden of Disease Compare. Life expectancy, healthy life expectancy. selected countries. Mexico (Mx): Institute for Health Metrics and Evaluation, 2017. https://vizhub.healthdata.org/gbdcompare/\#

11 Payne CF, Wong R. Expansion of disability across successive Mexican birth cohorts: a longitudinal modelling analysis of birth cohorts born 10 years apart. J Epidemiol Community Health 2019;73:900-5

12 Zunzunegui MV. Evolución de la discapacidad Y La dependencia. Una Mirada Internacional. Gac Sanit 2011;25:12-20.

13 Crimmins EM, Saito Y. Getting better and getting worse. J Aging Health 1993:5:3-36.

14 Díaz-Venegas C, Reistetter TA, Wang C-Y, et al. The progression of disability among older adults in Mexico. Disabil Rehabil 2016;38:2016-27.

15 Gómez-Dantés O, Sesma S, Becerril VM. Sistema de salud de México. Salud Publica mex 2011;53:220-32.

16 López Ortega MValencia Alnstituto Nacional de Geriatría, México, Mx2015Utilización de servicios de salud y gasto por atención. Diagnóstico actual y proyecciones a 2050.

17 Knaul FM, Arreola-Ornelas H, Méndez-Carniado O. [Financial protection in health: updates for Mexico to 2014]. Salud Publica Mex 2016;58:341-50.

18 Hadley J, Coverage I, Use MC. Insurance coverage, medical care use, and short-term health changes following an unintentional injury or the onset of a chronic condition. JAMA 2007;297:1073.

19 Wong R, Díaz JJ. Health care utilization among older Mexicans: health and socioeconomic inequalities. Salud Publica Mex 2007;49 Suppl 4:S505-14.

20 Beltrán-Sánchez H, Drumond-Andrade FC, Riosmena F. Contribution of socioeconomic factors and health care access to the awarenesss and treatment of diabetes and hypertension among older Mexican adults. Salud Publica Mex 2015;57:6.

21 Parker SW, Saenz J, Wong R. Health insurance and the aging: evidence from the Seguro popular program in Mexico. Demography 2018:55:361-86.

22 Mexican Health and Aging Study Web. Mexican health and aging study. Mexico (Mx): Mexican Health and Aging Study Web, C20122015. http://www.mhasweb.org/ Data.aspx

23 Katz S, Ford AB, Moskowitz RW, et al. Studies of illness in the aged. The index of ADL: a standardized measure of biological and psychosocial function. JAMA 1963;185:914-9.

24 Willekens F. Multistate analysis of life histories with R. New York: Springer, 2014: 308

25 Payne CF. Aging in the Americas: disability-free life expectancy among adults aged 65 and older in the United States, Costa Rica, Mexico, and Puerto Rico. J Gerontol B Psychol Sci Soc Sci 2018;73:337-48

26 Fries JF, Aging FJF. Aging, natural death, and the compression of morbidity. N Engl J Med 1980;303:130-5.

27 Gruenberg EM. The failures of success. 1977. Milbank Q 2005;83:779-800.

28 Manton KG. Changing concepts of morbidity and mortality in the elderly population. Milbank Mem Fund Q Health Soc 1982;60:183-244.

29 Patel KV, Peek MK, Wong R, et al. Comorbidity and disability in elderly Mexican and Mexican American adults. J Aging Health 2006;18:315-29.

30 Levy-Algazi S. ¿Universalización de la salud O de la seguridad social? Gaceta Med Mex 2011;147:455-68.

317 IMSS. Seguro de Salud para La familia. In: IMSS. Informe al Ejecutivo federal Y al Congreso de la Unión sobre La Situación Financiera Y Los Riesgos del Instituto Mexicano del Seguro social (2016-2017). Ciudad de México: Instituto Mexicano del Seguro Social, 2017: 185-90. 